\title{
A two-dimensional layer-averaged numerical model for turbidity currents
}

\author{
SHIHAO YANG ${ }^{1,2}$, YI AN ${ }^{1 *} \&$ QINGQUAN LIU ${ }^{3}$ \\ ${ }^{1}$ Institute of Mechanics, Chinese Academy of Sciences, Beijing 100190, China \\ ${ }^{2}$ School of Engineering Science, University of the Chinese Academy of Science, \\ Beijing 100049, China \\ ${ }^{3}$ School of Aerospace Engineering, Beijing Institute of Technology, Beijing \\ 100081, China
}

Y.A., 0000-0001-5024-7624

*Correspondence: anyi@imech.ac.cn

\begin{abstract}
Turbidity currents occur widely in submarine environments, but field-scale numerical simulations of the flow features have not been applied extensively. Here, we present a two-dimensional layer-averaged numerical model to simulate turbidity currents over an erodible sediment bed, and taking into consideration deposition, entrainment and friction. The numerical model was developed based on the open-source code, Basilisk, ensuring well-balanced and positivity-preserving properties. An adaptive spatial discretization was used, which allows multi-level refinement. The adaptive criterion is based on the dynamic features of the flow and sediment concentrations. The numerical scheme has a relatively high computational efficiency compared with models based on the Cartesian mesh. A hypothetical case based on a true large-scale landform (the Moroccan Turbidite System, offshore NW Africa) was studied. Compared with previous models, the current model accounted for the coupling between flow, sediment transportation and bed evolution. This approach may improve simulation results and also allow the simulation of complex field-scale landforms, while preserving the flow details.
\end{abstract}

Turbidity currents are particle-laden, gravity-driven underflows in which the particles are largely or wholly suspended by fluid turbulence (Meiburg \& Kneller 2010). Submarine turbidity currents can be caused by sediment failures on the slope, and the dilution and transformation of the resulting landslides and debris flows (Simpson 1997). Rivers, floods, tides and storms also contribute to its formation (Parsons et al. 2007; Meiburg \& Kneller 2010). Their impact on the ocean environment has attracted a lot of research interest.

There have been a large number of experiments on turbidity currents (e.g. Middleton 1966a, $b$, 1967; Parker 1982; Garcia 1993, 1994; Hallworth \& Huppert 1998; Alexander \& Mulder 2002; Imran et al. 2002; Baas et al. 2004; Sequeiros et al. 2009b; Chowdhury \& Testik 2011; Motanated \& Tice 2016). However, experimental investigations are inevitably limited by scale and their conclusions only provide approximations for use in field-scale events (Meiburg \& Kneller 2010; Imran et al. 2017). Direct field observations of turbidity currents are rarely reported in the literature because of the destructive power and unpredictability of turbidity currents (Khripounoff et al. 2003; Talling et al. 2012). Thus, numerical simulations are attractive because they provide details of the flow structures at an affordable cost. Numerical models for turbidity currents can be divided into three categories: layer-averaged, volume-averaged and NavierStokes (N-S) equation-based. Volume-averaged (box) models have been developed to fit the run-out distance against time, with empirical relationships between the current velocity and the Froude number. They are usually applied to understand laboratory lock-released turbidity currents, and are rarely used in field-scale events (Huppert 1998; Meiburg \& Kneller 2010; Chowdhury \& Testik 2011). The $\mathrm{N}-\mathrm{S}$ equation-based models are used to study the character of the turbulence and the vertical structure of the turbidity currents. However, with the unknown structure of the turbulence in the submarine environment and the high cost, these types of models are usually limited to small-scale situations with low Reynolds numbers (Huang et al. 2008; Firoozabadi et al. 2009; Sequeiros et al. 2010; Yam et al. 2011; Ooi et al. 2015). Therefore, layeraveraged (shallow-water) models are commonly

From: Lintern, D. G., Mosher, D. C., Moscardelli, L. G., Bobrowsky, P. T., Campbell, C., Chaytor, J. D., Clague, J. J., Georgiopoulou, A., Lajeunesse, P., Normandeau, A., Piper, D. J. W., Scherwath, M., Stacey, C. \& Turmel, D. (eds) Subaqueous Mass Movements. Geological Society, London, Special Publications, 477, 


\section{S. YANG ET $A L$.}

applied to study the macroscopic characteristics of turbidity currents, among which the one-layeraveraged models are most widely applied.

Parker et al. (1986) derived the depth-averaged governing equations for turbidity currents as the basic model of this kind. A number of decoupled or partially coupled models have been built where either the feedback impact or the bed deformation itself is considered (Zeng \& Lowe 1997a, b; Choi 1998; Imran et al. 1998; Bradford \& Katopodes 1999a, b; Fildani et al. 2006; Sequeiros et al. 2009a). Physically, the currents involve no, or weak, sediment transport with mild bed deformation. Conversely, real turbidity currents are often strongly non-conservative and rapidly exchange sediment with the environment. To fully consider the feedback impacts of bed deformation, $\mathrm{Hu} \&$ Cao (2009, 2012a) developed a fully coupled model for turbidity currents and solved it based on the finite-volume method.

Many numerical studies have been conducted using laboratory data. However, few have been used to study events at field-scale, and most of them are based on one-dimensional decoupled models (e.g. Hay 1987; Zeng \& Lowe 1997a, b; Pirmez \& Imran 2003; Fildani et al. 2006; Traer et al. 2015). Flows along canyons are commonly modelled in one dimension, and the flow condition near the mouths of canyons and abyssal plains is often unresolved. In addition, according to Wynn et al. (2002) and Talling et al. (2007), the erosion in this area is significant, so the feedback of the deformation of the bed on the current should be considered. To address these problems, two-dimensional fully-coupled models should be used in the field-scale simulation. However, due to the extreme aspect ratio of the canyon and the high requirements of grid size for front tracking, the computational cost of a classical (Cartesian) model is very high. To overcome these problems and bring the two-dimensional fully-coupled simulation of field-scale events into reality, we developed a new scheme of adaptive meshes based on the two-dimensional coupled model proposed by $\mathrm{Hu}$ et al. $(2012 a, b)$. We carried out a series of field-scale simulations based on the topography of the Agadir Canyon, and parts of Seine and Agadir abyssal plains, to test the applicability of this model in such highly erosive flows on complex topography.

It should be stated clearly that, similar to all other depth-averaged models, the model in this study has shortcomings in both the procedure of vertical integration and the empirical relationships. Different models of these two problems might lead to very different numerical results. Focusing on the methodology instead of fact-finding, this paper may not include all recent research findings in the section of field-scale simulation.

\section{Physical model}

\section{Governing equation}

The governing equations for turbidity currents over an erodible bed are the conservation of the mass, the momentum of the current and the mass of the sediment, respectively. A detailed derivation can be found in Parker et al. (1986) and $\mathrm{Hu} \& \mathrm{CaO}$ (2009). In this study, the model developed by $\mathrm{Hu}$ et al. (2012b) was used:

$$
h_{t}+(h u)_{x}+(h v)_{y}=e_{\mathrm{w}}|U|+\frac{(E-D)}{(1-p)}
$$

$$
\begin{aligned}
(h u)_{t} & +\left(h u^{2}+\frac{1}{2} g^{\prime} h^{2}\right)_{x}+(h u v)_{y} \\
= & -g^{\prime} h \frac{\partial z_{\mathrm{b}}}{\partial x}-\left(1+r_{\mathrm{w}}\right) u_{*}^{2}-\frac{u(E-D)\left(\rho-\rho_{0}\right)}{\rho(1-p)} \\
& -\frac{\rho_{\mathrm{w}}-\rho}{\rho} u e_{\mathrm{w}}|U| \\
(h v)_{t}+ & (h u v)_{x}+\left(h v^{2}+\frac{1}{2} g^{\prime} h^{2}\right)_{y} \\
= & -g^{\prime} h \frac{\partial z_{\mathrm{b}}}{\partial y}-\left(1+r_{\mathrm{w}}\right) v_{*}^{2}-\frac{v(E-D)\left(\rho-\rho_{0}\right)}{\rho(1-p)} \\
& -\frac{\rho_{\mathrm{w}}-\rho}{\rho} v e_{\mathrm{w}}|U| \\
& (h c)_{t}+(h u c)_{x}+(h v c)_{y}=E-D .
\end{aligned}
$$

The bed deformation is computed using the Exner equation:

$$
\frac{\partial z_{\mathrm{b}}}{\partial t}=-\frac{E-D}{1-p} .
$$

In equations (1-5), $t$ is time, $x$ and $y$ are horizontal coordinates, $h(x, y, t)$ is the depth of the current, $u(x$, $y, t)$ and $v(x, y, t)$ are the $x$ - and $y$-components of the layer-averaged velocities, respectively, $c(x, y, t)$ is the layer-averaged volumetric sediment concentration, and $z_{\mathrm{b}}(x, y, t)$ is the bed elevation. $|U|=\sqrt{u^{2}+v^{2}}$ is the total horizontal speed of the current, $g^{\prime}=R g c$ is the submerged gravitational acceleration, $g=9.81 \mathrm{~m} \mathrm{~s}^{-2}$ is the gravitational acceleration, $R=\left(\rho_{\mathrm{s}}-\rho_{\mathrm{w}}\right) / \rho$ is the submerged specific gravity, $\rho_{\mathrm{s}}$ and $\rho_{\mathrm{w}}$ are the density of the sediment and water, respectively, $\rho=\rho_{\mathrm{s}} c+\rho_{\mathrm{w}}(1-c)$ is the density of the water-sediment mixture, $p$ is the porosity of the bed, and $\rho_{0}=\rho_{\mathrm{w}} p+\rho_{\mathrm{s}}(1-p)$ is the density of the saturated bed. $E-D$ is the net exchange flux of the sediment, where $E$ is sediment 


\section{D LAYER-AVERAGED TURBIDITY CURRENT MODEL}

erosion and $D$ is sediment deposition. The vertical distributions of the concentration and the velocity are not explicitly considered. The shape factors, generated in the depth-integral step, are simply set as unity (Parker et al. 1987), which might problematic when the vertical distribution is far from uniform.

\section{Empirical relationships}

There are three sub-rules in the model that are governed by resistance, erosion and deposition, and entrainment of the surrounding water. In equations $(1-5), u_{*}=\sqrt{c_{\mathrm{D}} u|U|}$ and $v_{*}=\sqrt{c_{\mathrm{D}} v|U|}$ are the bed shear velocities in the $x$ - and $y$-directions, respectively, $c_{\mathrm{D}}$ is the bed drag coefficient with a range of 0.002-0.06 in common situations (Parker et al. 1987), $r_{\mathrm{w}}$ is the ratio of the upper surface resistance to bed resistance (Middleton 1966b; Parker et al. 1986; Zeng \& Lowe $1997 a, b)$, and $e_{\mathrm{w}}$ is a fluid entrainment coefficient on the upper surface of the currents, which is estimated by Parker et al. (1986) with the following equation:

$$
e_{\mathrm{w}}=\frac{0.00153}{0.0204+\mathrm{Ri}}
$$

where $\mathrm{Ri}=g^{\prime} h /|U|^{2}$ is the bulk Richardson number.

$$
E-D=\omega\left(E_{\mathrm{s}}-c_{\mathrm{b}}\right)
$$

is the difference between the sediment entrainment and the sediment deposition flux.

$$
\omega=\sqrt{\left(\frac{13.95 v}{d}\right)^{2}+1.09\left(\frac{\rho_{\mathrm{s}}}{\rho_{\mathrm{w}}-1}\right) g d}-\frac{13.95 v}{d}
$$

is the settling velocity of the sediment (Zhang \& Xie 1993), $v$ is the viscosity of water, $d$ is the mean diameter of the sediment particles, $c_{\mathrm{b}}=r_{\mathrm{b}} c$ is the local near-bed sediment concentration, $r_{\mathrm{b}}$ is an empirical coefficient with a value of $c$. 2.0 (Garcia 1993), and $E_{\mathrm{s}}$ is the near-bed concentration at the capacity condition, which can be estimated by the empirical formula (Parker et al. 1987; Fildani et al. 2006; Hu et al. 2012b):

$$
E_{\mathrm{s}}=\psi_{\mathrm{p}} \frac{A Z_{\mathrm{m}}^{5}}{1+(A / 0.4) Z_{\mathrm{m}}^{5}}
$$

where $A=1.3 \times 10^{-7}$ is an empirical coefficient, $Z_{\mathrm{m}}=\operatorname{Re}_{\mathrm{p}}^{0.5} U_{*} / \omega, \operatorname{Re}_{\mathrm{p}}=\sqrt{\operatorname{Rgd} d} / \nu$ is the particle Reynolds number, and $\psi_{\mathrm{p}}$ is a correction factor of $<1$. Parker's formula for sediment entrainment is an empirical formula for relatively coarse sediment, whereas the submarine sediment commonly consists of silt and clay. In the simulation of a field-scale event, the value of $\psi_{\mathrm{p}}$ was set to 0.15 , as suggested by $\mathrm{Hu}$ et al. $(2012 b)$; and $\psi_{p}=1$ is used when simulating the experimental cases.

\section{Numerical method}

The governing equations are written in a matrix form, as follows:

$$
\frac{\partial \vec{U}}{\partial t}+\frac{\partial \vec{F}(\vec{U})}{\partial x}+\frac{\partial \vec{G}(\vec{U})}{\partial y}=\overrightarrow{S_{\mathrm{b}}}+\overrightarrow{S_{\mathrm{f}}}
$$

with

$$
\begin{aligned}
& \vec{U}=\left[\begin{array}{c}
h \\
h u \\
h v \\
h c
\end{array}\right] \vec{F}=\left[\begin{array}{c}
h u \\
h u^{2}+\frac{1}{2} R g c h^{2} \\
h u v \\
h u c
\end{array}\right] \\
& \vec{G}=\left[\begin{array}{c}
h v \\
h v^{2}+\frac{1}{2} R g c h^{2} \\
h v c
\end{array}\right] \overrightarrow{S_{\mathrm{b}}}=\left[\begin{array}{c}
0 \\
-R c g h \frac{\partial z}{\partial x} \\
-R \operatorname{cgh} \frac{\partial z}{\partial y} \\
0
\end{array}\right] \\
& \overrightarrow{S_{\mathrm{f}}}=\left[\begin{array}{c}
e_{\mathrm{w}}|U|+\frac{E-D}{1-p} \\
-u_{*}^{2}\left(1+r_{\mathrm{w}}\right)-u \frac{E-D}{1-p} \frac{\rho_{0}-\rho}{\rho}-\frac{\rho_{\mathrm{w}}-\rho}{\rho} u e_{\mathrm{w}}|U| \\
-v_{*}^{2}\left(1+r_{\mathrm{w}}\right)-v \frac{E-D}{1-p} \frac{\rho_{0}-\rho}{\rho}-\frac{\rho_{\mathrm{w}}-\rho}{\rho} v e_{\mathrm{w}}|U| \\
E-D
\end{array}\right]
\end{aligned}
$$

Next, equations (5), (10) and (11) were solved using a finite-volume method based on a SaintVenant solver in the open-source code, Basilisk; a new Harten-Lax-van Leer contact (HLLC) solver was conducted for the Riemann Problem with the volumetric sediment concentration; and a standard splitting method was used to add the source term $\vec{S}_{f}$. The well-balanced property has been solved by the origin Saint-Venant solver, and the preservation of the positivity of the current depth and the volumetric sediment concentrations are guaranteed through special processing (see the subsection on 'HLLC solver, source terms, positivity-preserving property and other issues' later in this section). (A scheme that does not have the well-balanced property would result in numerical oscillation where currents stay still over rough ground, especially near the front of currents; and schemes solving shallow-water equations could lead to a negative 


\section{S. YANG ET AL.}

height of current. This non-physical height would not occur if a scheme is positivity preserved.)

\section{Saint-Venant solver in Basilisk}

Basilisk is a free software program for the solution of partial differential equations on adaptive Cartesian meshes developed by Popinet (2011). The Saint-Venant solver in Basilisk was originally designed for tsunami modelling, which solved equation (10) with $R=1, c=1$ and $S_{\mathrm{f}}=0$. The standard HLLC solver is used to solve the homogeneous problem with the topographical source term to be considered with a particular choice of reconstruction of the bottom topography, which ensures the wellbalanced property and preserves the positivity of the depth (Audusse et al. 2004). A MUSCL-type un-split discretization combined with a predictorcorrector time-stepping scheme is used to solve the two spatial dimensional problems (Popinet 2011). The adaptive meshes based on quadtree spatial discretization are used in Basilisk.

\section{HLLC solver, source terms,}

\section{positivity-preserving property and other issues}

The new Riemann Problem with the volumetric sediment concentration coupled in the term of gravity is as follows (in $x$-split form):

$$
\begin{gathered}
\frac{\partial \vec{U}}{\partial t}+\frac{\partial \vec{F}(\vec{U})}{\partial x}=\frac{\partial \vec{U}}{\partial t}+A(\vec{U}) \frac{\partial \vec{U}}{\partial x}=0 \\
\vec{U}(t=0, x)=\left\{\begin{array}{l}
U_{\mathrm{L}}, x<0 \\
U_{\mathrm{R}}, x>0
\end{array}\right.
\end{gathered}
$$

where $\vec{U}$ and $\vec{F}(\vec{U})$ are defined by equation (11), and $A(\vec{U})$ represents the Jacobian matrix of the flux function $\vec{F}(\vec{U})$. It can be proved that equation (12) is strictly hyperbolic: that is, one can find a complete set of eigenvectors. Four eigenvalues of this system are easily calculated as $u, u$ and $u \pm \sqrt{R c g h}$. Therefore, a modified HLLC solver can be built simply by substituting gravity, $g$, in the standard solver of the Saint-Venant system with $R c g$ to estimate the two external waves, and adding variables, which include the volumetric sediment concentration in $\vec{U}$ and $\vec{F}$ (see Toro 2001 for details).

The topographical source term $S_{\mathrm{b}}$ can be added by the well-balanced scheme proposed by Audusse et al. (2004), which has been produced using Basilisk codes. After the Riemann Problem is solved, the full system equation - equation (11) - with complex source term $S_{\mathrm{f}}$ is then solved by a standard splitting scheme (Toro 2001). Finally, the bed deformation equation - equation (5) - is solved with a first-order explicit scheme.

The positivity preservation of the depth of currents has been solved with the Basilisk codes. However, positivity preservation of volumetric sediment concentration has not been ensured nor proved. Using numerical tests, we found that negative values of concentration are always located at the interfaces of currents where the height is small, or arise from interpolation when adaptive meshes are used and their absolute values are usually small (commonly less than $10^{-10}$ in our test cases where the characteristic concentration is around $1 \%$ ). Therefore, values of sediment concentration that numerically become negative with absolute values of less than $10^{-10}$ were artificially set to 0 . Note that $c=0$ and $h=0$ should be the same based on the definition; therefore, we take one of them as a criterion for 'no-current' where the other variables should either have no definition or are set to 0 . This issue is associated with the interfaces of currents, the interpolation in the adaptations and the instability of the scheme.

The tree-based adaptive meshing scheme is provided by the Basilisk codes. Discretizations were performed with $3 \times 3$ stencils and the governing equations were solved by traversing the stencils over the domain. Given an error threshold eps, local refinement occurs whenever the local estimate of the interpolation error is greater than eps. Conversely, local coarsening occurs if the error for all siblings is less than eps/k $(k=2)$. The four siblings are then removed and replaced by the parent grid point. Interpolation occurs at locations where the level of the grids varies in order to calculate values at ghost points out of the boundary of the stencils. The refinement or coarsening occurs if the gradient of the variables concerned varies too much between the levels of the meshes. Interpolation error represents the difference in the gradient between two levels, which is associated with the interpolation scheme and the level of the grids. The details of the adaptive meshing scheme used in Basilisk can be found in Popinet (2011).

\section{Validations}

\section{A well-balanced property over irregular beds with flow discontinuity}

The first test case was used to check the wellbalanced property in the present model. The wellbalanced property is associated with the capability of the numerical scheme to solve shallow-water movement to preserve static water conditions over an irregular topography. A non-well-balanced scheme would produce spurious waves, which leads to an incorrect prediction of sediment concentration in 


\section{D LAYER-AVERAGED TURBIDITY CURRENT MODEL}

these areas. The well-balanced property is evaluated in the flow domain over irregular beds, and also at the boundaries between the flow and non-flow zones. To this end, two islands with different altitudes are defined as:

$$
\begin{gathered}
z_{\mathrm{b}}=\max \left(0,0.24 \exp \left(-2\left[(x-2)^{2}+(y-4)^{2}\right]\right),\right. \\
\left.0.1 \exp \left(-5\left[(x-6)^{2}+(y-4)^{2}\right]\right)\right)
\end{gathered}
$$

in an $8 \times 8 \mathrm{~m}$ domain on a set of Cartesian meshes by level 10 ( $2^{10}$ grids along one direction). The initial current surface elevation is $0.15 \mathrm{~m}$, and the initial sediment concentration is 0.04 . Sediment entrainment and deposition are not considered here. The computed current surface and the sediment concentration profiles remain stationary for a sufficiently long time (e.g. until $t=100 \mathrm{~s}$ in the study) (Fig. 1). Therefore, the modified solver also ensures the wellbalanced property over irregular beds with or without flow discontinuity.

\section{Turbidity currents in a flume over a non-erodible bed}

This test case was used to verify the accuracy of the proposed numerical model. The experiments to model the turbidity currents with or without an inner hydraulic jump were reported in Garcia (1993, 1994). The experiments were conducted in a $0.3 \mathrm{~m}$-wide and $11.6 \mathrm{~m}$-long channel, which consisted of a $5 \mathrm{~m}$-long inclined bed with a slope of $0.08\left(4.6^{\circ}\right)$ in the upstream part, followed by a
$6.6 \mathrm{~m}$-long horizontal bed. The flume was filled with clear water as the ambient fluid and initially with no sediment. A turbidity current of known density was released at the top of the inclined bed at a known rate, and the current began to flow down along the slope at $t=0 \mathrm{~s}$. The inlet current thickness was set to $3 \mathrm{~cm}$ with a specific layer-averaged inlet velocity.

The computational domain was $11.6 \times 0.4 \mathrm{~m}$ on a set of Cartesian meshes of level 9. The finer mesh leads to essentially the same numerical results. The parameters of the selected experimental runs in Garcia (1993, 1994), GLASSA2 and MIX6, are given in Table 1. Because the initial bed is rigid with no sand, the updated bed level calculated from equation (5) should be no less than the initial bed level. The inlet current was supercritical, and the critical current condition was used $(\mathrm{Ri}=1)$ at the downstream boundary because of the free-fall condition in the experiment.

Figure $2 \mathrm{a}$ and $\mathrm{b}$ shows the comparison between the computed and measured results (only MIX6) of the elevation of the current in GLASSA2 and MIX6, respectively. Figure $2 \mathrm{c}$ and $\mathrm{d}$ shows the comparisons between the computed and measured results of deposition thickness against distance. Good agreement is observed for the selected runs. A hydraulic jump was observed in MIX6, but not in GLASSA2, and the same phenomenon can be seen in our simulations. The jump condition was satisfied when there was a hydraulic jump in MIX6. This result demonstrates the accuracy of the model.

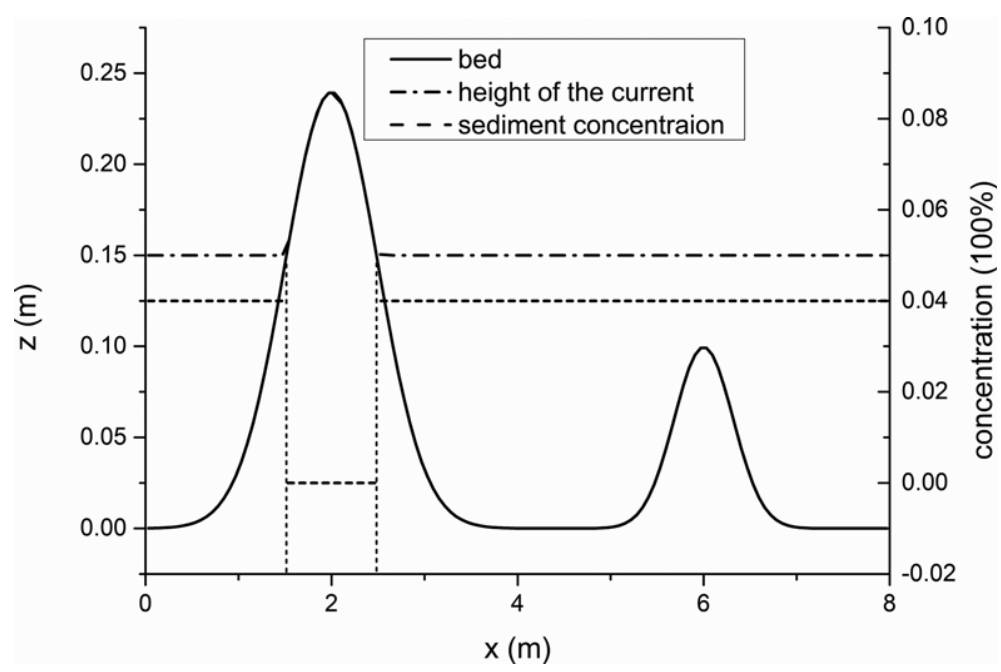

Fig. 1. Plot of bed, height of the current and sediment concentration along the axis to check the well-balanced property over irregular beds with flow discontinuity. The initial concentration is $0.04 \%$, the initial height of still fluid is $0.15 \mathrm{~m}$. The height of the fluid and concentration after $100 \mathrm{~s}$ are plotted with the bed. 
S. YANG $E T A L$.

Table 1. Parameters used in the simulation of GLASSA2 and MIX6

\begin{tabular}{lcccccccc}
\hline Case & $u_{0}\left(\mathrm{~m} \mathrm{~s}^{-1}\right)$ & $h_{0}(\mathrm{~cm})$ & $c_{0}(\%)$ & $p$ & $\rho_{\mathrm{s}} / \rho_{\mathrm{w}}$ & $d_{\mathrm{s}}(\mu \mathrm{m})$ & $c_{\mathrm{D}}$ & End time (min) \\
\hline GLASSA2 & 0.083 & 3 & 0.3390 & 0.5 & 2.65 & 30 & 0.01 & 30 \\
MIX6 & 0.11 & 3 & 0.0109 & 0.5 & 2.65 & 27 & 0.025 & 30 \\
\hline
\end{tabular}

\section{Field-scale event: Moroccan turbidity currents}

\section{Description and numerical settings}

Talling et al. (2007), Wynn et al. (2012) and Stevenson et al. (2013) reported the results of shallow sediment cores from the Agadir Basin, and the Seine and Madeira abyssal plains offshore NW Africa. Sediment samples contained a sequence of deposits spanning the past $200 \mathrm{kyr}$. Their work showed that a turbidity current, which was generated by a landslide on the Moroccan continental margin near the head of Agadir Canyon, probably produced a debris flow.
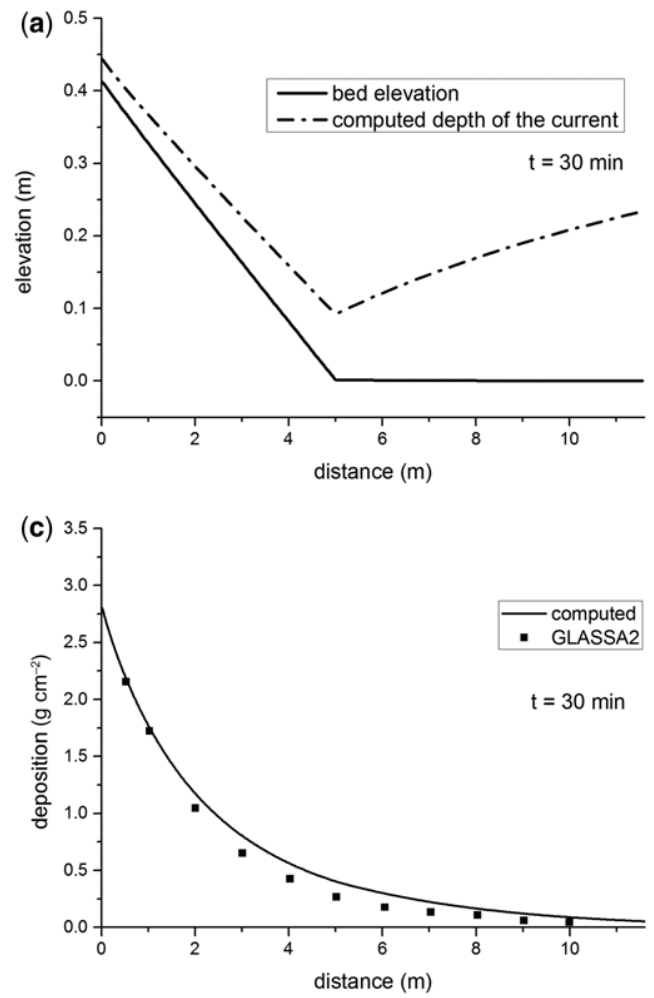

This flow comes from transformation by a remarkably small, but abrupt, decrease in the seafloor gradient at the base of the exit ramp located at the mouth of the Agadir Canyon. The turbidity current eroded hemipelagic sediment at locations 200-300 m above the canyon floor by up to $4 \mathrm{~m}$. As mentioned previously, most models for turbidity currents do not consider deformation of bed elevation or the impact of it on flows. The present model considered this effect in the simulation of these kinds of field-scale erosive turbidity currents. Figure 3 shows the topography of the study area (image downloaded from the GEBCO_2014 Grid (30 arc-second interval)) by the British Oceanographic Data Centre.

(b)

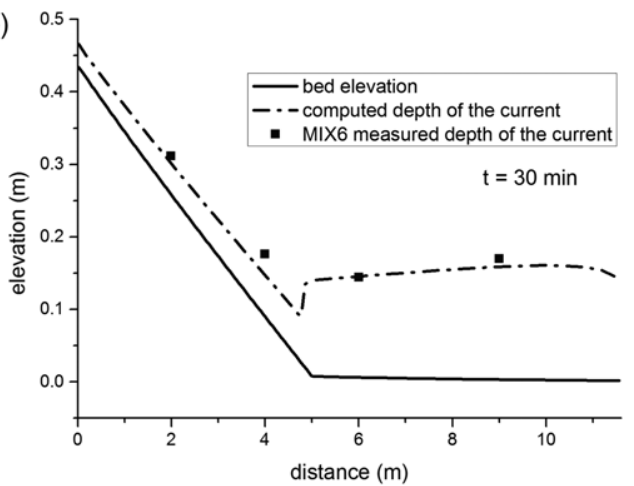

(d)

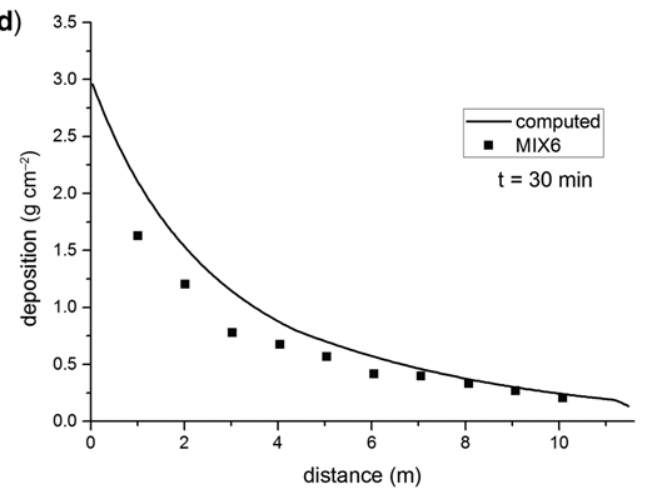

Fig. 2. (a) \& (b) Comparison between computed and measured results (only MIX6) of the elevation of the current in GLASSA2 (Garcia 1993) and MIX6 (Garcia 1994), respectively. (c) \& (d) Comparisons between the computed and measured results of deposition thickness against distance. Time labelled in the figures is the time of the flows in Garcia's experiments. There are no data of elevation in GLASSA2, and no hydraulic jump was recorded. 
2D LAYER-AVERAGED TURBIDITY CURRENT MODEL

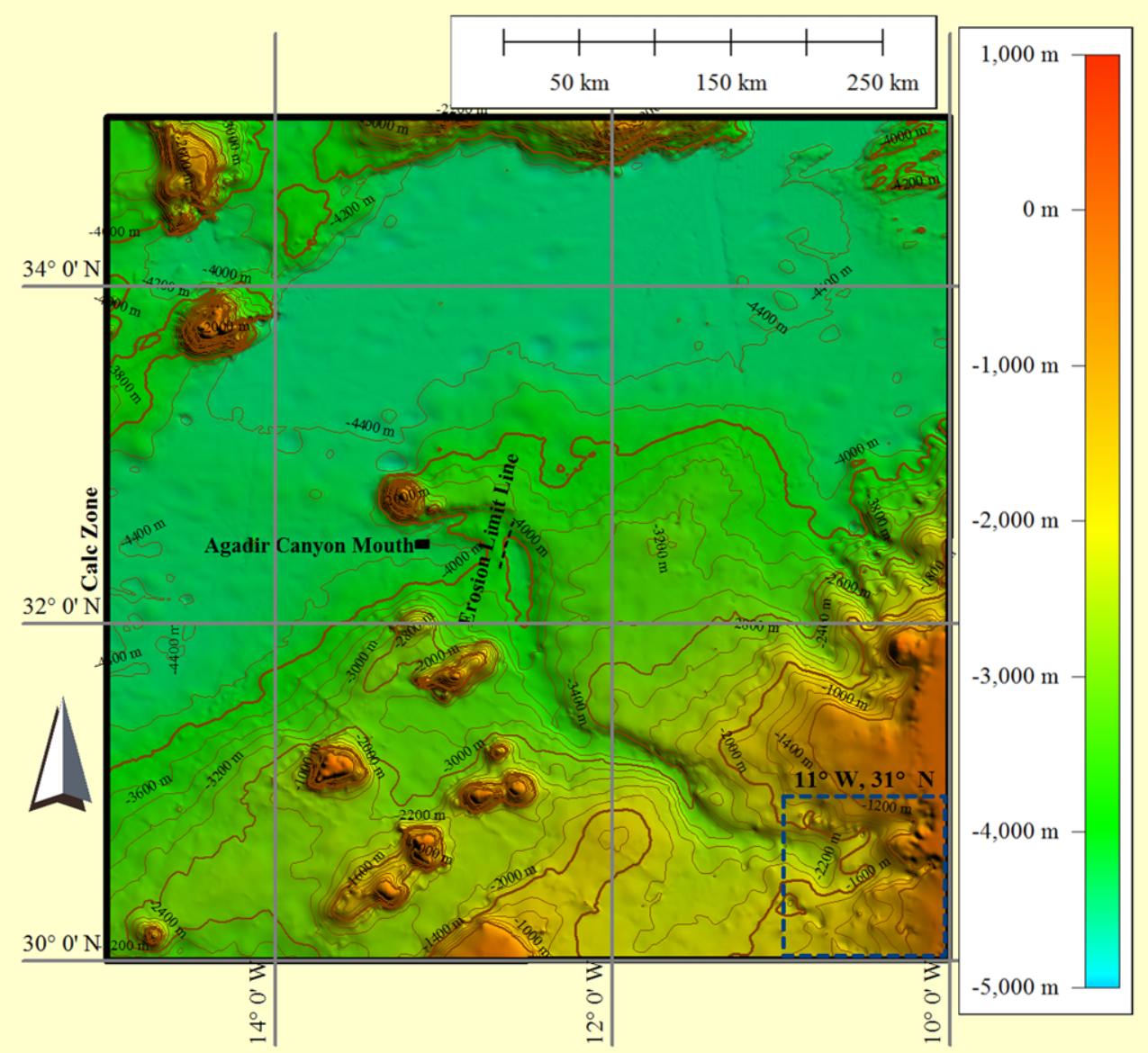

Fig. 3. Terrain of the Agadir Canyon, offshore NW Africa. The computational domain is depicted by the solid box $\left(15^{\circ} \mathrm{W}-10^{\circ} \mathrm{W}, 35^{\circ} \mathrm{N}-30^{\circ} \mathrm{N}\right)$, and the initial locking dam is indicated by the dashed box, where the coordinate of the top left-hand corner is labelled in the figure. The mouth of Agadir Canyon and the limit of major erosion reported by Talling et al. (2007) are labelled. The data of topography were downloaded from the GEBCO_2014 Grid (30 arc-second interval) at the British Oceanographic Data Centre.

Next, a series of simulations of turbidity currents based on the terrain in this area are presented. The simulations demonstrate the ability of this model to study the field-scale turbidity currents with notable bed deformation. We are not able to simulate the flows that actually occurred but use a hypothetical event because the flow conditions are based on interpretations of the ancient sediment samples. This assumption in the flow condition is also one of the main challenges when modelling field-scale turbidity currents (Talling et al. 2012, 2015). If we conduct the initial condition by setting the flux of the current at some inlet, it is impossible to determine the location and the duration of the source. The inlet velocity and the depth of the currents are also unavailable,
Table 2. Initial parameters of the cases in Group 2

\begin{tabular}{lcc}
\hline Case & $\begin{array}{c}\text { Initial } \\
\text { concentration } \\
(\%)\end{array}$ & $\begin{array}{c}\text { Initial } \\
\text { volume } \\
\left(\mathrm{km}^{3}\right)\end{array}$ \\
\hline 1 & 1 & 171.5 \\
2 & 3 & 171.5 \\
3 & 5 & 171.5 \\
4 & 7 & 171.5 \\
5 & 1 & 31.2 \\
6 & 3 & 31.2 \\
7 & 5 & 31.2 \\
8 & 7 & 31.2 \\
\hline
\end{tabular}


Downloaded from http://sp.lyellcollection.org/ by guest on May 24, 2018

\section{S. YANG ET AL.}

(a1)

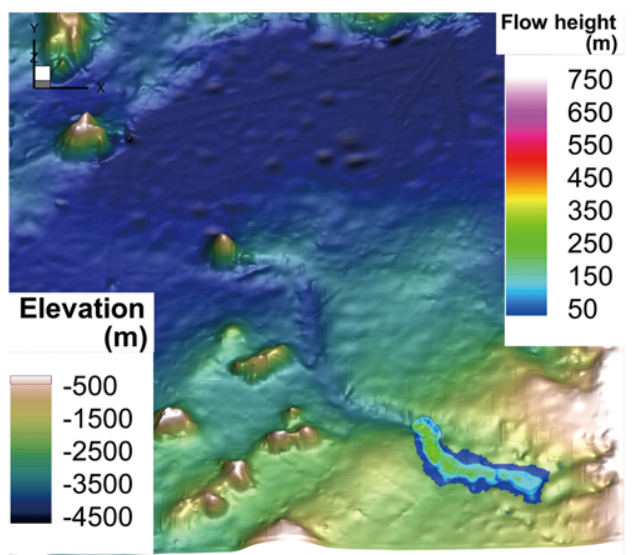

(a2)

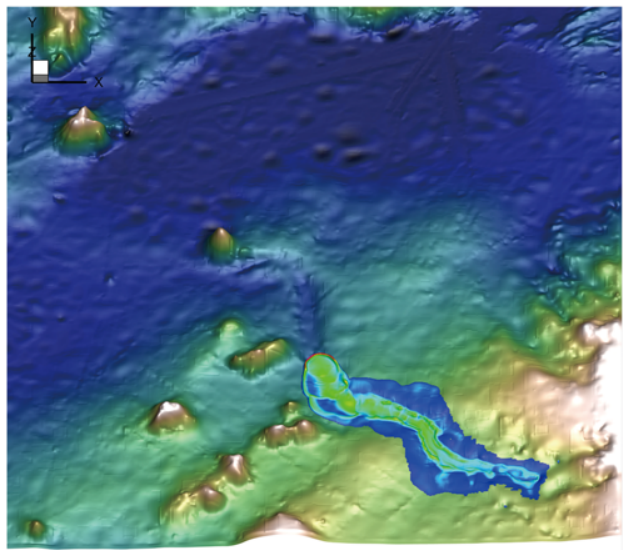

(a3)

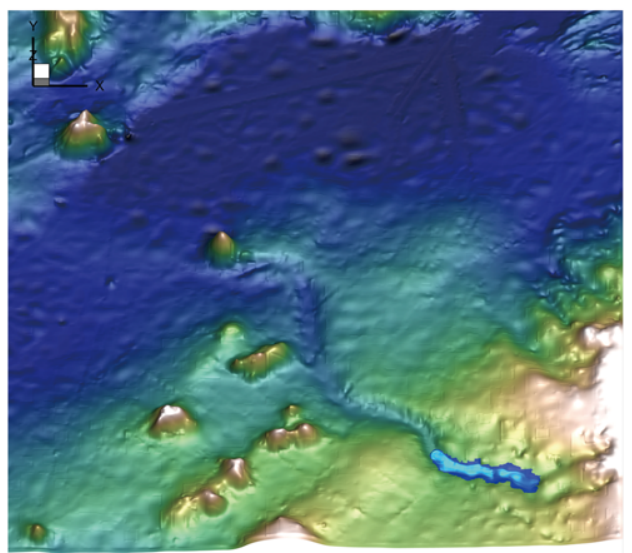

(b1)

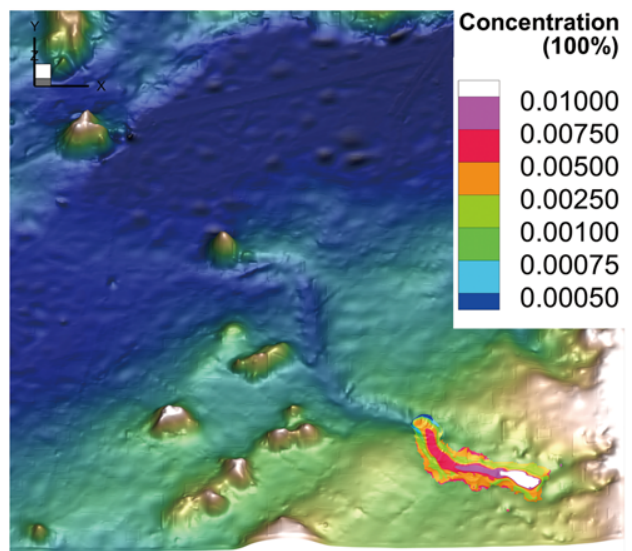

(b2)

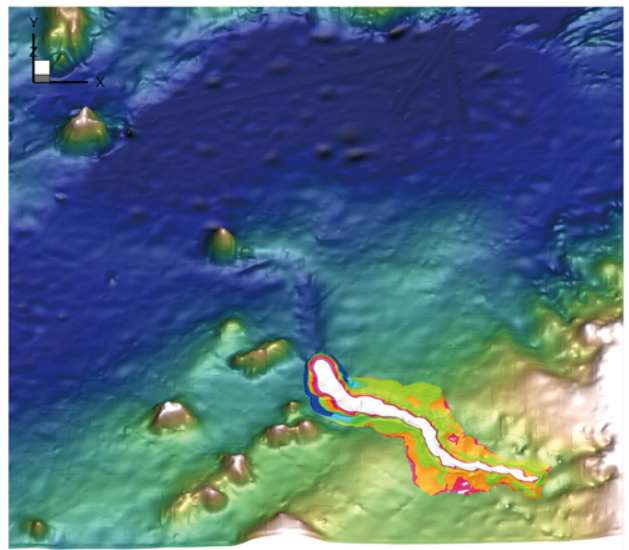

(b3)

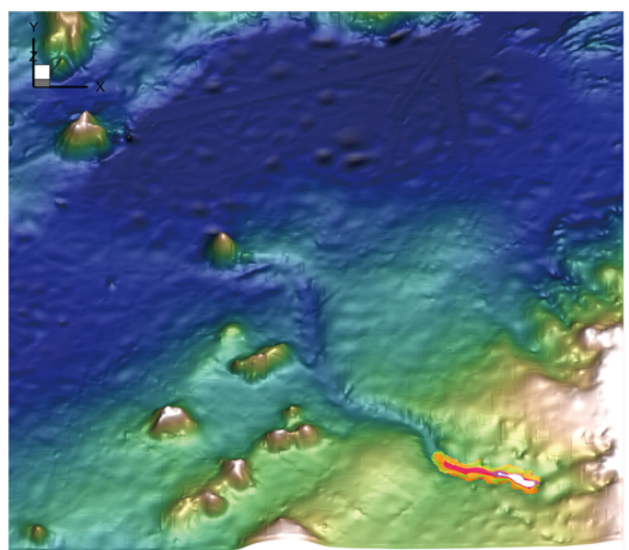

Fig. 4. Distribution of the height of currents and sediment concentration at $t=6 \mathrm{~h}$. Two different colourmaps are used to display the landscape with flow height and sediment concentration. Snapshots of height of currents are in column (a), snapshots of sediment concentration are in column (b). Row (1) represents the distribution of the variables in case 1, row (2) shows results in case 4 and row (3) shows results in case 5. The legends are only in row (1) of each column. 
Downloaded from http://sp.lyellcollection.org/ by guest on May 24, 2018

2D LAYER-AVERAGED TURBIDITY CURRENT MODEL

(a1)

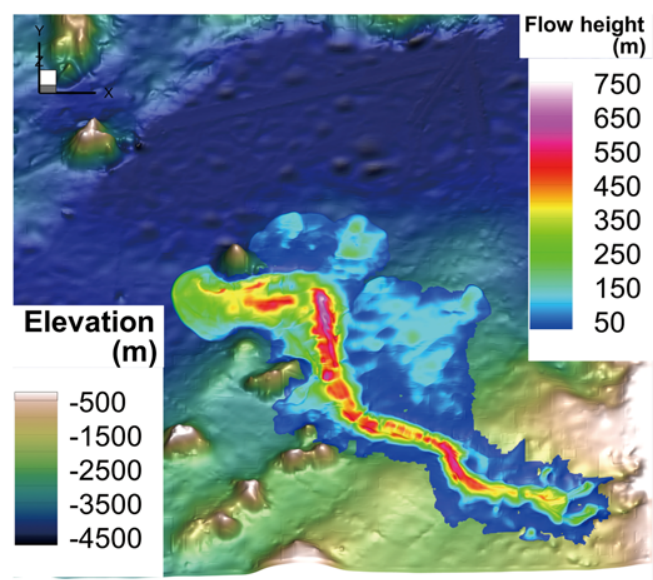

(a2)

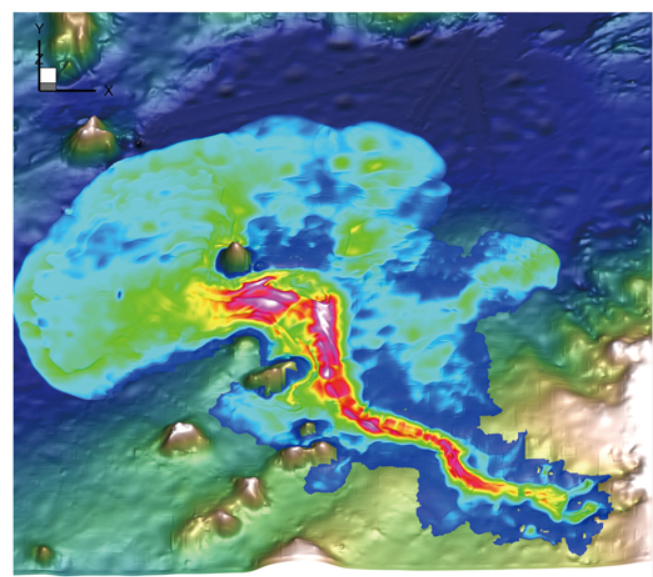

(a3)

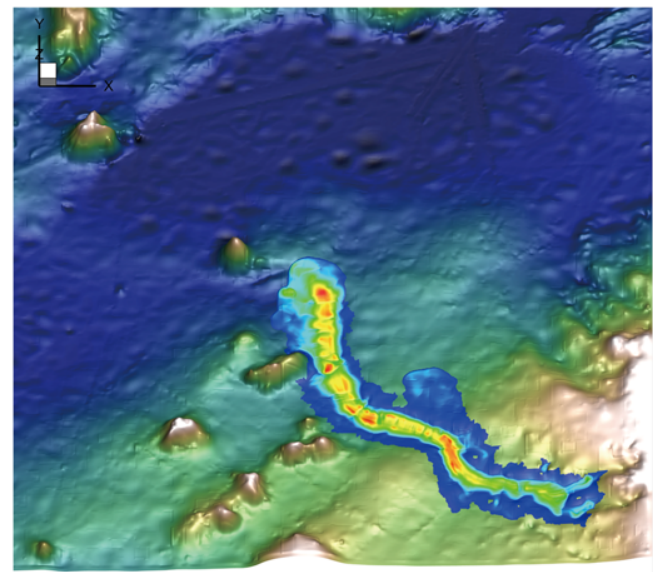

(b1)

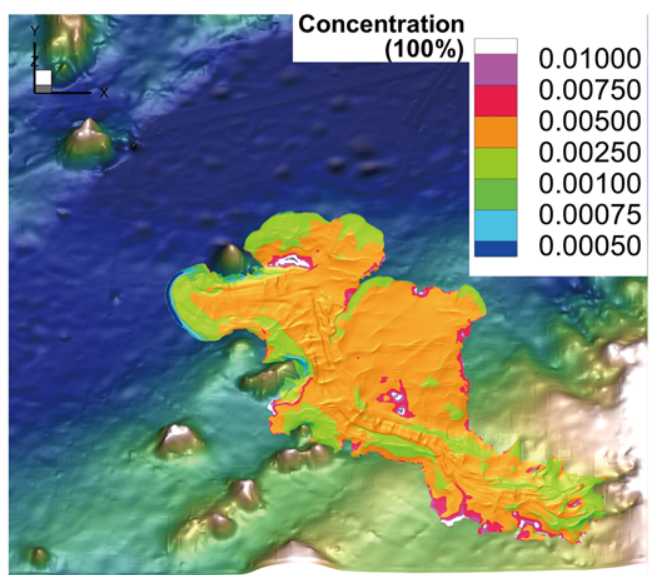

(b2)

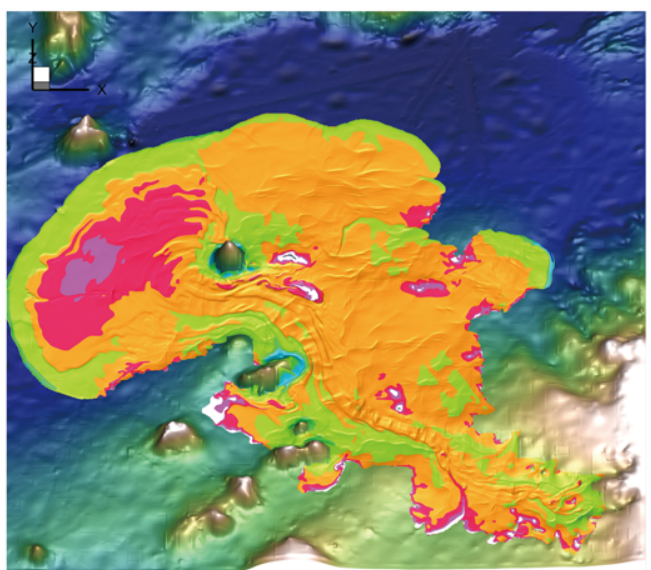

(b3)

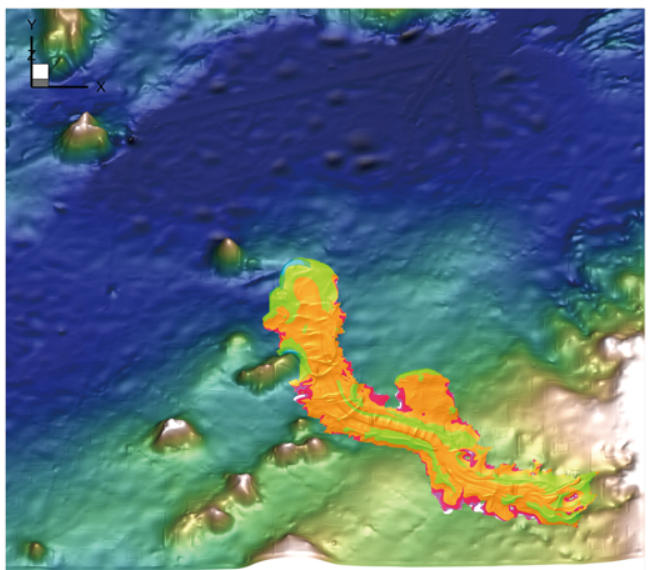

Fig. 5. Distribution of the height of currents and sediment concentration at $t=30 \mathrm{~h}$. Other settings are the same as in Figure 4. 


\section{S. YANG ET AL.}

which describe the process where the turbidity currents form in the post-failure period of submarine landslides. As a result, simulated cases cannot be compared strictly and directly with the event as described by geologists (e.g. Wynn et al. 2002, 2012; Talling et al. 2007). Details of the event are also not clear, except for deposit samples from the canyon and the erosion depth near the mouth of the canyon, which, unfortunately, are not sufficient to verify or validate the numerical model.

We set initial conditions in a lock-released manner and conducted three groups of simulations. The first group contained six cases where several levels (8-12, which means $2^{8}-2^{12}$ grids in each direction) of the Cartesian meshes were used to check the mesh independence. The second group contained eight cases where Cartesian meshes are used, and a single case of the adaptive meshes that was used to analyse its computational efficiency. The initial volume of the water-sediment mixture and the volumetric sediment concentration are changed to study the impact of these two parameters on the flows, as shown in Table 2. The third group contained two cases, where maximal concentration and size of the initial volume were used with and without bed deformation.

The bed drag coefficient, $c_{\mathrm{D}}$, was set to 0.004 (Talling et al. 2007) and the mean diameter, $d$, of the sediment particles was set to $20 \mu \mathrm{m}$ (Talling et al. 2007; Hu et al. 2012a, b; Wynn et al. 2012). $\rho_{\mathrm{s}}$ and $\rho_{\mathrm{w}}$ were set to 2650 and $1035 \mathrm{~kg} \mathrm{~m}^{-3}$, respectively. The porosity of the bed, $p$, was 0.5 . The computational domain and the initial locking dam are also shown in Figure 3, where the space was filled with the water-sediment mixture below $-2200 \mathrm{~m}$ for the initial volume of $171.5 \mathrm{~km}^{3}$ and below $-2400 \mathrm{~m}$ for a volume of $31.2 \mathrm{~km}^{3}$, respectively. The physical time for the simulation was 1.25 days, by which time the currents in all cases had reached the mouth of the canyon.

Note that the value of $p=0.5$ is a bit high for sand, which could be questionable. We did not find any data for porosity values in the study area. As a reference value reported by Flemings et al. (2012) at the Ursa Basin, porosity declines from 80 to $40 \%$ with increasing depth below seabed; and it

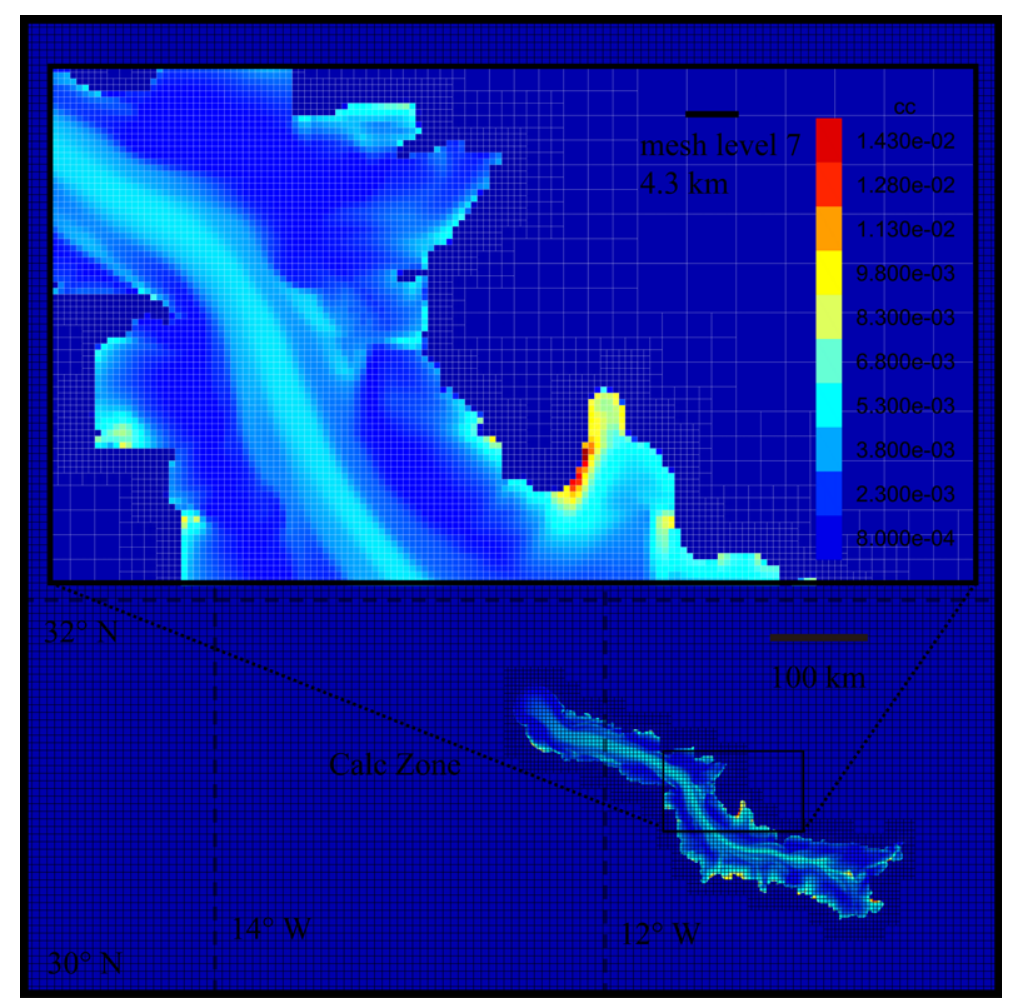

Fig. 6. Snapshot of meshes in case 1 at $t=18 \mathrm{~h}$ in the adaptive case. The colourmap shows the distribution of sediment concentration (in 100\%), which is written as 'cc' in the legend. The coarsest meshes are in level $7\left(2^{7}\right.$ grids in each direction in the domain on Cartesian meshes) and the finest meshes are in level 10. 


\section{D LAYER-AVERAGED TURBIDITY CURRENT MODEL}

remains approximately $40 \%$ when the depth is greater than $100 \mathrm{~m}$. We have run a test case by setting $p=0.4$ and keeping the other parameters the same as in case 8 . The results (not shown here) are slightly different from the one with $p=0.5$; so we let $p=0.5$ in the present study.

\section{Results and discussion}

In the field and in the simulations for Agadir Canyon, turbidity currents reach the mouth of the canyon, decelerate and spread over the abyssal plain. The strongest turbidity current in the simulations is produced in case 4, with the highest initial sediment concentration of $7 \%$ and the largest initial volume of water-sediment mixture of $171.5 \mathrm{~km}^{3}$; while case 5 (row (3) in Figs 4 \& 5) is the weakest. When the initial sediment concentration remains the same (1\%), the front of the current in case 1 moves more rapidly (c. $3 \mathrm{~km} / \mathrm{h}$ ) than in case 5 . where the initial volume in case 1 is 4.5 times greater than that in case 5 . When the initial volume remains the same, the current with the higher initial concentration in case 4 propagates and spreads much more rapidly than in case 1 .

From rows (1) and (2) in Figures 4 and 5, we can see that under such high initial volumes the turbidity current floods over the middle of the canyon. Talling et al. (2007) reported a major erosional hiatus in cores 37 and 38 (see their supplementary fig. 2). A limit of major erosion is suggested, which means (a1)

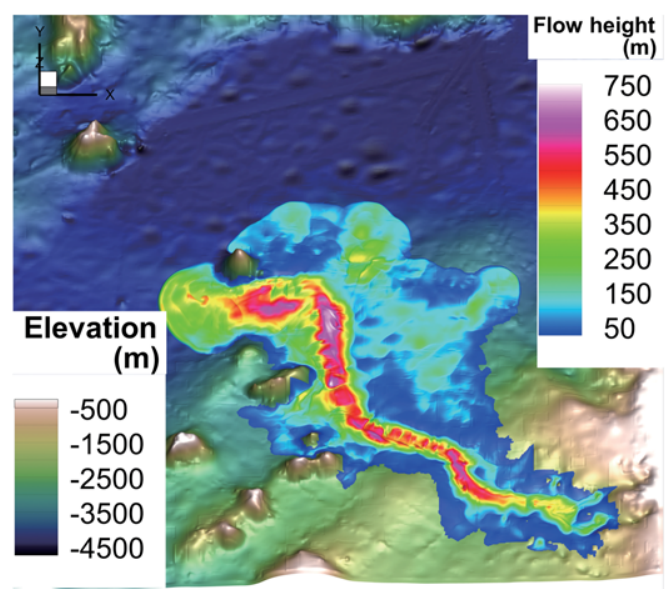

(a2)

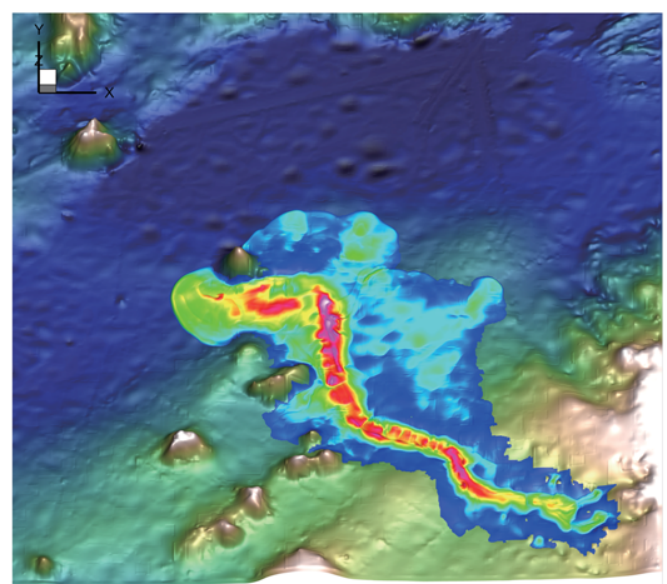

(b1)

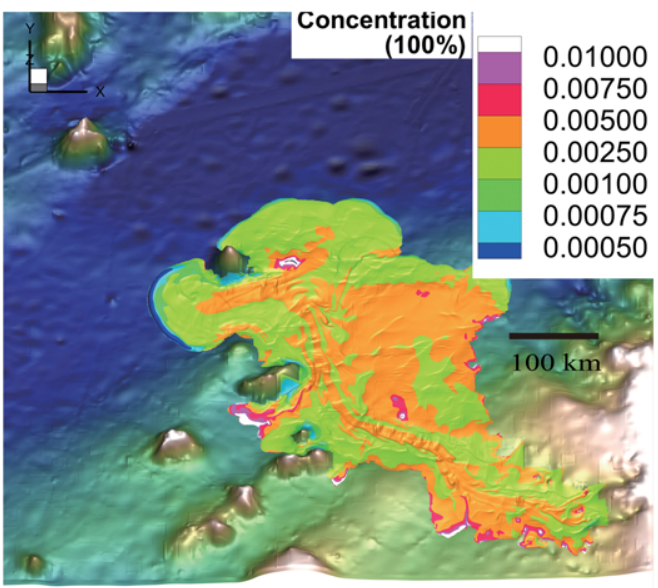

(b2)

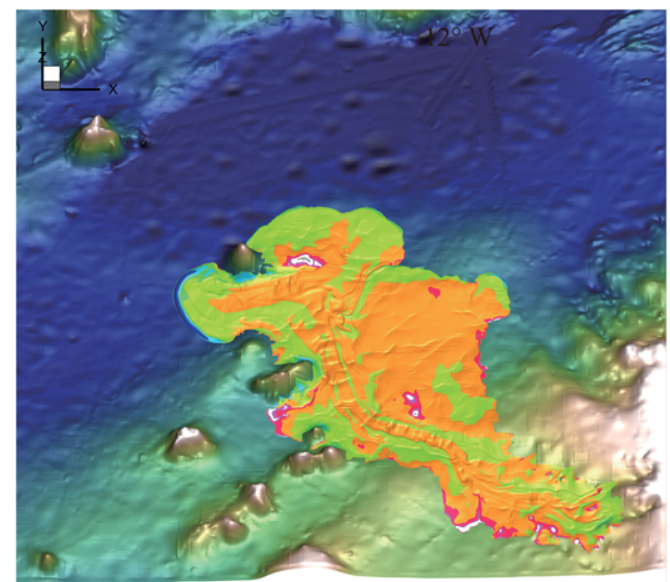

Fig. 7. Distribution of the height of currents and sediment concentration of the test case for $r_{\mathrm{w}}$ at $t=30 \mathrm{~h}$. Snapshots of height of currents are in column (a), snapshots of sediment concentration are in column (b). Row (1) represents the distribution of the variables where $r_{\mathrm{w}}=0$, row (2) shows results where $r_{\mathrm{w}}=0.2$. The legends are only in row (1) of each column. 


\section{S. YANG ET AL.}

that the area of erosion at that location was limited. Thus, a current with a negligible speed out of the limit line at this spot, which would cause a wider area of erosion, should not occur. We find that only case 5 can potentially occur in reality, where both the initial sediment concentration $(1 \%)$ and volume $\left(31.2 \mathrm{~km}^{3}\right)$ are the smallest in our simulation. If the initial condition, where the water-sediment mixture is given in a way of lock-release, is reasonable and the current fully generates in the upper canyon at one time, then the initial volume of the turbidity current produced by the landslide should not be greater than approximately $50 \mathrm{~km}^{3}$. Otherwise, the sediment concentration should be less than $1 \%$, or the initial current speed should not exceed approximately $4 \mathrm{~m} \mathrm{~s}^{-1}$ (estimated by $\sqrt{R g c_{0} h_{0}}$, where a value for $h_{0}$ of $c$. $60 \mathrm{~m}$ represents the initial averaging depth of the water-sediment mixture).

Figure 6 shows the meshes at $t=18 \mathrm{~h}$ in case 1 when the mesh is adaptive. The coarsest meshes are in level 7 in the periphery of the flow, and the finest meshes are in level 10 near the front of and inside the currents. The threshold eps is set as $0.1 \mathrm{~m}$ for $h$, $0.5 \mathrm{~m}$ for $h+z_{\mathrm{b}}$ and $0.001 \%$ for $c$. Results of this simulation on adaptive meshes are the same as those on Cartesian meshes of level 10, while computing time is much shorter (about five times faster).

Note that the effect of resistance in the upper interface, expressed by $r_{\mathrm{w}}$, was not considered in many models. As shown by Middleton (1966b), for large underflows on low slopes, it is probably small because of the relatively small Fr number and large Re number. In the simulations, $r_{\mathrm{w}}=0.43$ is used as suggested by $\mathrm{Hu}$ et al. (2012b). We conducted two cases to check the sensitivity of this parameter, by changing it to 0 and 0.2 and keeping the other parameters the same as case 1 . Compared with the flows in case 1 , where $r_{\mathrm{w}}=0.43-(\mathrm{a} 1, \mathrm{~b} 1)$ in Figure 5 - it turns out that the main structure of the height of currents and sediment concentration is not sensitive to this parameter within this range, as shown in Figure 7.

The volume of erosion in our simulations was calculated from the deformation of the bed. Figure 8 shows that there is a positive correlation between the volume of erosion and the initial sediment concentration with the initial volume of the sediment-water mixture (i.e. the volume of the turbidity current). A large initial volume of turbidity currents with a low sediment concentration and a small initial volume with a high concentration can reach the same total erosion threshold during the same duration ( 1.25 days in the present simulations: Fig. 8a). Figure 8b shows the approximate powerfunction relationship between the volume of erosion and the initial sediment volume. The form and parameters of this relationship depend on many other physical factors, such as topography, grain
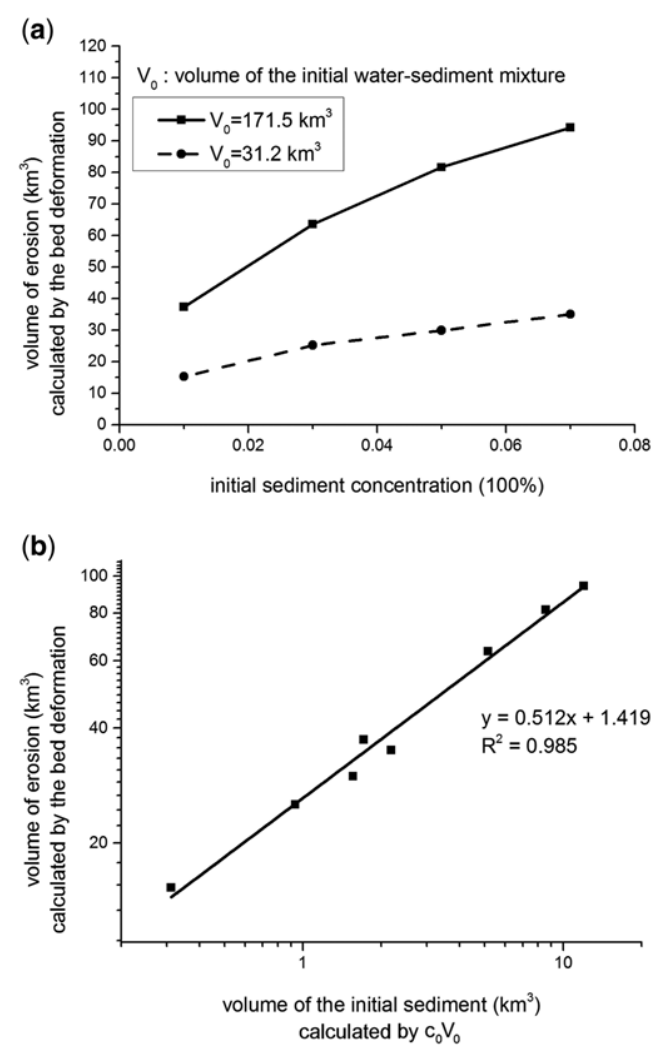

Fig. 8. (a) Relationships between the volume of erosion and the initial volume and initial concentration. (b) A power-function correlation between the initial volume of sediment and the volume of erosion. The initial volume of sediment is calculated by multiplying the initial volumetric sediment concentration, $c_{0}$, with the initial volume of water-sediment mixture, $V_{0}$. The volume of erosion is calculated by integrating the reduction in bed height.

size, porosity of the bed and, potentially, the duration. Further research must be conducted to analyse the functional relationship between the dimensionless volume of erosion scaled by the initial sediment volume and other parameters, which could be achieved by a parameter study using a simpler basin configuration.

We can see from Figure 9 that the deposition is stronger near the original releasing spot in case 4 (c. $2 \mathrm{~m}$ ), with a large initial volume of watersediment mixture and a high concentration. However, the bed deformation remains almost the same in cases under variable initial conditions.

Compared with the limiting area of erosion at the lower Agadir Canyon (Talling et al. 2007), the erosional area in case 4 , which is designed as an extreme 


\section{D LAYER-AVERAGED TURBIDITY CURRENT MODEL}
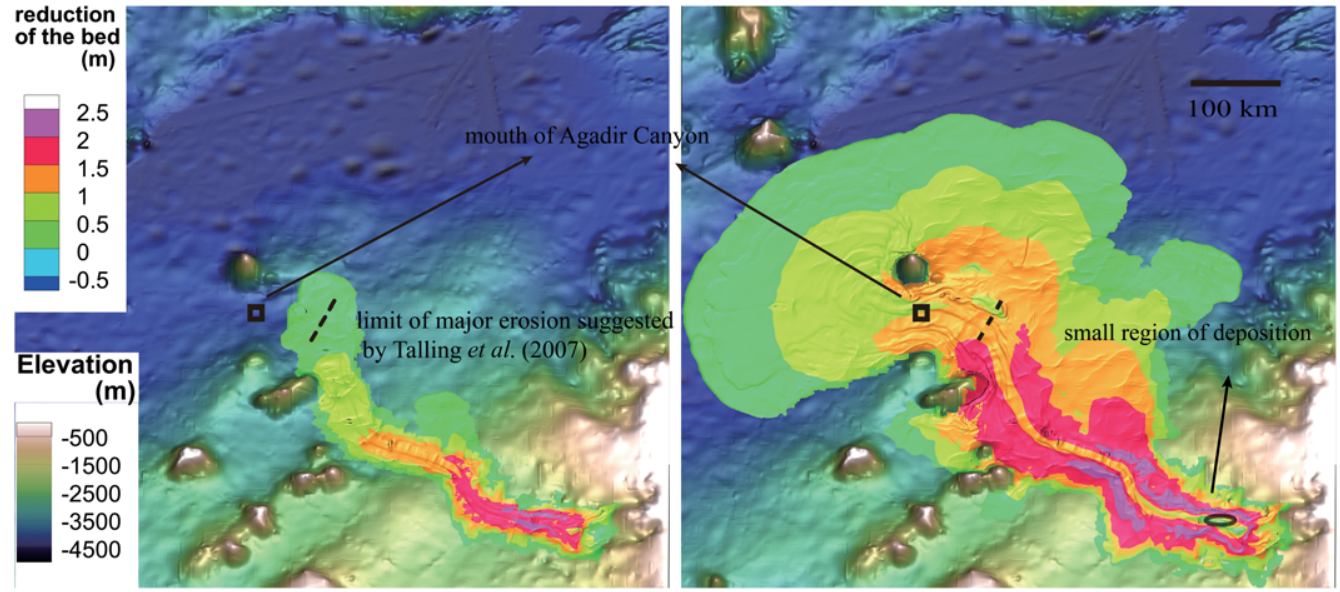

Fig. 9. Reduction in the bed height in case 5 (left-hand side) and case 4 (right-hand side) at $t=30 \mathrm{~h}$. Two different colourmaps are used to display the landslide and the values of the reduction in bed height by erosion (and negative values for deposition, which is slight except for a small region near the releasing spot in case 4). The mouth of Agadir Canyon is labelled with a rectangle, and the limit of major erosion reported by Talling et al. (2007) is labelled with a dashed line. The area where a large amount of erosion occurs should not far exceed the end points of the dashed line at that spot.

situation, exceeds the limit, which means that the current of case 4 probably overestimates erosion. Case 5 is the only one in our simulations that satisfies the criterion in which the erosional area is concentrated along the canyon, which means that relatively smaller turbidity events are sufficient to reproduce observations. In the upper canyon, large positive values of bed deformation are caused by high speed and long duration. Negative values are at the wall of levees and near the releasing spot in case 5. Talling et al. (2007) reported that up to $4 \mathrm{~m}$ of hemipelagic sediment was eroded in locations $200-300 \mathrm{~m}$ above the canyon floor, while our simulation reached $2 \mathrm{~m}$ of erosion, which is comparable in magnitude.

Note that the law of erosion is formulated based on data from constant-flux laboratory flume tests (Parker et al. 1987). It has not been validated at the field scale. The erosion patterns are sensitive to grain size and the correction factor, $\psi_{\mathrm{p}}$. We ran a test case with $\psi_{\mathrm{p}}=1$ (the original Parker formula: Parker et al. 1987) and a grain size of $70 \mu \mathrm{m}$, keeping the other settings the same as those in case 1 . The reduction in the bed height can reach $20 \mathrm{~m}$ in the upper canyon. The new empirical parameter $\psi_{\mathrm{p}}$ probably affects patterns of sediment exchange as it includes the physical and geometrical differences between the material in the original experiments and the cases we study. However, the literature on this is rare, which limits discussion of the effect of grain size in the current model. So, even though it is an aspect of concern, we did not study the effect of grain size in the current paper.
The greatest depth of erosion is about $2.5 \mathrm{~m}$, which is much less than the height of the currents, and the simulations were limited to 1.25 days rather than to the final deposition stage. Therefore, coupling the bed deformation with the flow made no obvious difference. The test cases in Group 3 also confirmed this point. However, in the test case with a larger grain size where the erosion was strong, the feedback effect of bed deformation became stronger.

Finally, we give an estimation of the effect of the Coriolis force according to Cossu \& Wells (2010) and Cossu et al. (2015). The rotational effect can be estimated by the Rossby number: Ro $=U / L f$, where $U$ is the mean horizontal speed of the current and $L$ is a characteristic length scale. The Coriolis parameter, $f=2 \Omega \sin \varphi$ at latitude $\varphi, \Omega=7.29 \times$ $10^{-5} \mathrm{rad} \mathrm{s}^{-1}$, is the Earth's rotation about its axis. The study area is at about $32^{\circ} \mathrm{N}$, so $f=7.73 \times 10^{-5}$ $\operatorname{rad~s}^{-1}$. The length of Agadir Canyon is $L_{\mathrm{C}}=$ $460 \mathrm{~km}$ and the width is in the range of $W_{\mathrm{C}}=$ 5-15 km (Wynn et al. 2002). The length of the valley $L_{\mathrm{V}}$ is approximately $400 \mathrm{~km}$, so the sinuosity can be defined as the ratio of the channel length to the valley length, $L_{\mathrm{C}} / L_{\mathrm{V}}=1.15$, which indicates that the channel is nearly straight (Wynn et al. 2007). The averaged radius of curvature for the canyon, $R$, is calculated to be $c$. $625 \mathrm{~km}$. The averaged downstream speed varied from 4 to $8 \mathrm{~m} \mathrm{~s}^{-1}$ between the cases. So the Rossby number $\mathrm{Ro}_{L}$ (with the characteristic length scale given by $L_{\mathrm{C}}$ ) is in the range of $0.11-0.22<<1$, which indicates that the Coriolis 


\section{S. YANG ET AL.}

force does deflect the flow. The Rossby number $\mathrm{Ro}_{W}$ (with the characteristic length scale given by $W_{\mathrm{C}}$ ) is in the range of 3.4-20.7, smaller than $|R / W|>40$, which indicates that the Coriolis force is important and gives rise to flow patterns that explain the observations of levee height asymmetry. Indeed, the Agadir Canyon shows a continuously higher right levee because of the Coriolis force (Wynn et al. 2002; Talling et al. 2007). While the Coriolis force may significantly affect the flow structure, the present model, for the sake of simplicity, does not include the effect of the Coriolis force, but this will be revised in the near future.

\section{Summary}

In this study, a solver for a two-dimensional layeraveraged numerical model to simulate turbidity currents over an erodible sediment bed was built based on the Saint-Venant solver in the open-source code Basilisk. A modified HLLC solver for the new Riemann Problem was proposed. The model takes deposition, entrainment and friction into consideration, and numerically solves the full model with these complex source terms using a standard splitting method. The numerical scheme ensures wellbalanced and positivity-preserving properties. An adaptive spatial discretization based on the dynamic features of the flow and sediment concentrations was used, which allowed multi-level refinement and coarsening. This adaptive scheme has a remarkably high computational efficiency compared with models built on a Cartesian mesh.

Hypothetical cases on a true large-scale landform (the Moroccan Turbidite System, offshore NW Africa) were studied. Based on the threshold of erosion near the mouth of the Agadir Canyon proposed by Talling et al. (2007), the assumed initial sediment concentration and the initial volume of the turbidity current were analysed in the simulations. A powerfunction correlation was found between the initial volume of the sediment and the volume of erosion. The area where currents strongly erode the bed is sensitive to the initial condition. However, local bed deformation remains within the same order of magnitude, while initial conditions vary. A depth of erosion of up to $2.5 \mathrm{~m}$ was obtained in the simulation, which is reasonable compared with observations made by Talling et al. (2007). The feedback effect seems unimportant in the current particular situation; therefore, models without bed deformation might be acceptable, while the proposed coupled model might be more appropriate if erosion is strong.

Acknowledgements We thank two reviewers, Professor David Cole Mosher and Professor Benjamin Kneller, for their valuable suggestions and comments which definitely improved this study. We also thank Reetta Saikku, PhD, from Liwen Bianji, Edanz Editing China (www.liwenbianji.cn/ac) for editing the English text of a draft of this manuscript.

Funding This work was financially supported by the National Natural Science Foundation of China (grant Nos 11672310 and 11432015 to Y. An and Q. Liu, respectively), the National Basic Research Programme of China (grant No. 2014 CB04680202 to Q. Liu), and the National Key Research and Development Plan (grant No. 2016YFC0303708 to Q. Liu).

\section{References}

Alexander, J. \& Mulder, T. 2002. Experimental quasi-steady density currents. Marine Geology, 186, $195-210$.

Audusse, E., Bouchut, F., Bristeau, M.-O., Klein, R. \& Perthame, B. 2004. A fast and stable well-balanced scheme with hydrostatic reconstruction for shallow water flows. Siam Journal on Scientific Computing, 25, 2050-2065.

BaAs, J.H., Van Kesteren, W. \& Postma, G. 2004. Deposits of depletive high-density turbidity currents: a flume analogue of bed geometry, structure and texture. Sedimentology, 51, 1053-1088.

BradFord, S.F. \& Katopodes, N.D. 1999a. Hydrodynamics of turbid underflows. I: formulation and numerical analysis. Journal of Hydraulic Engineering, 125, 1006-1015.

BRADFORD, S.F. \& Katopodes, N.D. 1999b. Hydrodynamics of turbid underflows. II: aggradation, avulsion, and channelization. Journal of Hydraulic Engineering ASCE, 125, 1016-1028.

CHо, S.U. 1998. Layer-averaged modeling of twodimensional turbidity currents with a dissipativeGalerkin finite element method - Part I: formulation and application example. Journal of Hydraulic Research, 36, 339-362.

Chowdhury, M.R. \& Testik, F.Y. 2011. Laboratory testing of mathematical models for high-concentration fluid mud turbidity currents. Ocean Engineering, 38, 256-270.

Cossu, R. \& Wells, M.G. 2010. Coriolis forces influence the secondary circulation of gravity currents flowing in large-scale sinuous submarine channel systems. Geophysical Research Letters, 37, L17603.

Cossu, R., Wells, M.G. \& Peakall, J. 2015. Latitudinal variations in submarine channel sedimentation patterns: the role of Coriolis forces. Journal of the Geological Society, London, 172, 161-174, https://doi.org/10. 1144/jgs2014-043

Fildani, A., Normark, W.R., Kostic, S. \& Parker, G. 2006. Channel formation by flow stripping: large-scale scour features along the Monterey East Channel and their relation to sediment waves. Sedimentology, 53, 1265-1287.

Firoozabadi, B., Afshin, H. \& Aram, E. 2009. Threedimensional modeling of density current in a straight channel. Journal of Hydraulic Engineering - ASCE, 135, 393-402. 


\section{D LAYER-AVERAGED TURBIDITY CURRENT MODEL}

Flemings, P.B., John, C. \& Behrmann, J.H. 2012. Expedition 308 synthesis: overpressure, consolidation and slope stability on the continental slope of the Gulf of Mexico. In: Flemings, P.B., Behrmann, J.H., John, C.M. \& the Expedition 308 Scientists (eds) Proceedings of the Integrated Ocean Drilling Program, Volume 308. Integrated Ocean Drilling Program Management International, Inc., Washington, DC, https://doi.org/ 10.2204/iodp.proc.308.215.2012

GARCIA, M.H. 1993. Hydraulic jumps in sediment-driven bottom currents. Journal of Hydraulic Engineering ASCE, 119, 1094-1117.

GARCIA, M.H. 1994. Depositional turbidity currents laden with poorly sorted sediment. Journal of Hydraulic Engineering - ASCE, 120, 1240-1263.

Hallworth, M.A. \& Huppert, H.E. 1998. Abrupt transitions in high-concentration, particle-driven gravity currents. Physics of Fluids, 10, 1083-1087.

HAY, A.E. 1987. Turbidity currents and submarine channel formation in Rupert Inlet, British Columbia 2: the roles of continuous and surge-type flow. Journal of Geophysical Research: Oceans, 92, 2883-2900.

Hu, P. \& CAO, Z.X. 2009. Fully coupled mathematical modeling of turbidity currents over erodible bed. Advances in Water Resources, 32, 1-15.

Hu, P., Cao, Z.X. \& Pender, G. 2012a. Well-balanced two-dimensional coupled modelling of submarine turbidity currents. Proceedings of the Institution of Civil Engineers - Maritime Engineering, 165, 169-188.

Hu, P., Cao, Z.X., Pender, G. \& Tan, G.M. 2012b. Numerical modelling of turbidity currents in the Xiaolangdi reservoir, Yellow River, China. Journal of Hydrology, 464, 41-53.

Huang, H.Q., Imran, J. \& Pirmez, C. 2008. Numerical study of turbidity currents with sudden-release and sustained-inflow mechanisms. Journal of Hydraulic Engineering - ASCE, 134, 1199-1209.

HuPPERT, H.E. 1998. Quantitative modelling of granular suspension flows. Philosophical Transactions of the Royal Society A - Mathematical Physical and Engineering Sciences, 356, 2471-2496.

Imran, J., Parker, G. \& Katopodes, N. 1998. A numerical model of channel inception on submarine fans. Journal of Geophysical Research: Oceans, 103, 1219-1238.

Imran, J., Parker, G. \& HarfF, P. 2002. Experiments on incipient channelization of submarine fans. Journal of Hydraulic Research, 40, 21-32.

Imran, J., Khan, S.M., Pirmez, C. \& Parker, G. 2017. Froude scaling limitations in modeling of turbidity currents. Environmental Fluid Mechanics, 17, 159-186.

Khripounoff, A., Vangriesheim, A., Babonneau, N., Crassous, P., Dennielou, B. \& Savoye, B. 2003. Direct observation of intense turbidity current activity in the Zaire submarine valley at $4000 \mathrm{~m}$ water depth. Marine Geology, 194, 151-158.

Meiburg, E. \& Kneller, B. 2010. Turbidity currents and their deposits. Annual Review of Fluid Mechanics, 42, 135-156.

Middeton, G.V. 1966a. Experiments on density and turbidity currents. 1. Motion of the head. Canadian Journal of Earth Sciences, 3, 523.

Middleton, G.V. 1966 b. Experiments on density and turbidity currents. 2. Uniform flow for density currents. Canadian Journal of Earth Sciences, 3, 627.
Middleton, G.V. 1967. Experiments on density and turbidity currents. 3. Deposition of sediment. Canadian Journal of Earth Sciences, 4, 475.

Motanated, K. \& Tice, M.M. 2016. Hydraulic evolution of high-density turbidity currents from the Brushy Canyon Formation, Eddy County, New Mexico inferred by comparison to settling and sorting experiments. Sedimentary Geology, 337, 69-80.

Ooi, A., Zgheib, N. \& Balachandar, S. 2015. Direct numerical simulation of three-dimensional gravity current on a uniform slope. Frontiers in Fluid Mechanics Research, 126, 372-376.

PARKER, G. 1982. Conditions for the ignition of catastrophically erosive turbidity currents. Marine Geology, 46, 307-327.

Parker, G., Fukushima, Y. \& Pantin, H.M. 1986. Selfaccelerating turbidity currents. Journal of Fluid Mechanics, 171, 145-181.

Parker, G., Garcia, M., Fukushima, Y. \& Yu, W. 1987. Experiments on turbidity currents over an erodible bed. Journal of Hydraulic Research, 25, 123-147.

Parsons, J., Friedrichs, C. ET AL. 2007. The mechanics of marine sediment gravity flows. In: NitTrouer, C.A., Austin, J.A., Field, M.E., Kravitz, J.H., Syvitski, J.P.M. \& WiBerg, P.L. (eds) Continental Margin Sedimentation: from Sediment Transport to Sequence Stratigraphy. International Association of Sedimentologists, Special Publications, 37, 275-337.

Pirmez, C. \& Imran, J. 2003. Reconstruction of turbidity currents in Amazon Channel. Marine and Petroleum Geology, 20, 823-849.

PopinET, S. 2011. Quadtree-adaptive tsunami modelling. Ocean Dynamics, 61, 1261-1285.

Sequeiros, O.E., Cantero, M.I. \& Garcia, M.H. $2009 a$. Sediment management by jets and turbidity currents with application to a reservoir for flood and pollution control in Chicago, Illinois. Journal of Hydraulic Research, 47, 340-348.

Sequeiros, O.E., Naruse, H., Endo, N., Garcia, M.H. \& PARKER, G. 2009b. Experimental study on selfaccelerating turbidity currents. Journal of Geophysical Research: Oceans, 114, C05025.

Sequeiros, O.E., Spinewine, B., Beaubouef, R.T., Sun, T., Garcia, M.H. \& PARKeR, G. 2010. Bedload transport and bed resistance associated with density and turbidity currents. Sedimentology, 57, 1463-1490.

Simpson, J.E. 1997. Gravity Currents in the Environment and Laboratory. Cambridge University Press, Cambridge.

Stevenson, C.J., Talling, P.J. et al. 2013. The flows that left no trace: very large-volume turbidity currents that bypassed sediment through submarine channels without eroding the sea floor. Marine and Petroleum Geology, 41, 186-205.

TALLING, P.J., WynN, R.B. ET AL. 2007. Onset of submarine debris flow deposition far from original giant landslide. Nature, 450, 541-544.

Talling, P.J., Masson, D.G., Sumner, E.J. \& Malgesini, G. 2012. Subaqueous sediment density flows: depositional processes and deposit types. Sedimentology, 59, 1937-2003.

TAlling, P.J., Allin, J. ET AL. 2015. Key future directions for research on turbidity currents and their deposits. Journal of Sedimentary Research, 85, 153-169. 


\section{S. YANG ET AL.}

Toro, E.F. 2001. Shock-Capturing Methods for FreeSurface Shallow Flows. John Wiley, Chichester, UK.

Traer, M.M., Fildani, A., McHargue, T. \& Hilley, G.E. 2015. Simulating depth-averaged, one-dimensional turbidity current dynamics using natural topographies. Journal of Geophysical Research: Earth Surface, 120, 1485-1500.

Wynn, R.B., Weaver, P.P.E., Masson, D.G. \& Stow, D.A.V. 2002. Turbidite depositional architecture across three interconnected deep-water basins on the northwest African margin. Sedimentology, 49, 669-695.

Wynn, R.B., Cronin, B.T. \& Peakall, J. 2007. Sinuous deep-water channels: genesis, geometry and architecture. Marine and Petroleum Geology, 24, 341-387.

Wynn, R.B., Talling, P.J., Masson, D.G., Le Bas, T.P., Cronin, B.T. \& Stevenson, C.J. 2012. The influence of subtle gradient changes on deep-water gravity flows: a case study from the Moroccan turbidite system. In: Prather, B.E., Deptuck, M.E., Mohrig, D., Van
Hoorn, B. \& Wynn, R.B. (eds) Application of the Principles of Seismic Geomorphology to ContinentalSlope and Base-of-Slope Systems: Case Studies from Seafloor and Near-Seafloor Analogues. SEPM Special Publications, 99, 371-383.

Yam, K., McCaffrey, W.D., Ingham, D.B. \& Burns, A.D. 2011. CFD modelling of selected laboratory turbidity currents. Journal of Hydraulic Research, 49, 657-666.

ZENG, J.J. \& Lowe, D.R. 1997a. Numerical simulation of turbidity current flow and sedimentation. 1. Theory. Sedimentology, 44, 67-84.

ZENG, J.J. \& Lowe, D.R. 1997b. Numerical simulation of turbidity current flow and sedimentation. 2. Results and geological applications. Sedimentology, 44, 85-104.

Zhang, R. \& XIE, J. 1993. Sedimentation Research in China: Systematic Selections. China Water and Power Press, Beijing, China. 